\title{
Response to the Letter to the Editor: Prevalence, Risk Factors and Assessment of Depressive Symptoms in Patients With Systemic Sclerosis
}

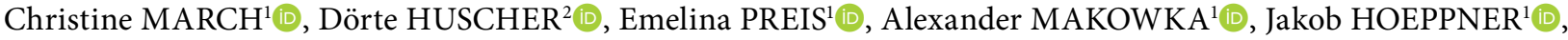

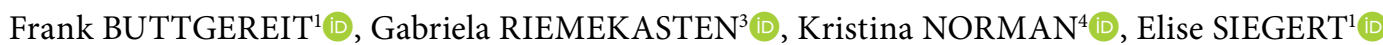 \\ ${ }^{1}$ Department of Rheumatology and Clinical Immunology, Charité-Universitatsmedizin Berlin, Berlin, Germany \\ ${ }^{2}$ Department of Rheumatology, Deutsches Rheumaforschungszentrum, Berlin, Germany \\ ${ }^{3}$ Department of Rheumatology, Universitätsklinikum Schleswig Holstein, Campus Lübeck, Lübeck, Germany \\ ${ }^{4}$ Charité-Universitatsmedizin Berlin, Research Group on Geriatrics, Berlin, Germany
}

Thank you very much for your interest in our article "Prevalence of Depressive Symptoms in Patients with Systemic Sclerosis". We value your contribution to central questions on prevalence and relevance of depressive disorders in this field and are glad to respond to your concerns.

We are fully aware that the Major Depression Inventory (MDI) does not allow us to diagnose depressive disorders or to estimate its prevalence among patients with systemic sclerosis (SSc). At no point in our study did we claim that we assessed the prevalence of depression in SSc. ${ }^{1}$

You might be right that the scientific value of estimating the prevalence of MDI-relevant items is limited. However, as we mention in the discussion of our paper, we want to raise the awareness for mental health issues in SSc without providing psychiatric diagnoses, measuring significant impairment or estimating the prevalence of depressive disorders in SSc. Also, we did not evaluate the MDI as a screening tool for depressive disorders in SSc. Our primary interest was to assess the number of patients suffering from depressive symptoms and who might thus benefit from systematic evaluation of mental health issues.

We share your concerns regarding the overestimation of depressive disorders by depression symptom questionnaires. However, we chose the MDI because it is known to be a rather conservative measure for depressive symptoms according to comparative studies using other self-report questionnaires. ${ }^{2}$ At the same time, it is short enough to be handed out to patients in an out-patient setting. Hence, it might potentially serve as a screening tool; to evaluate this was not the aim of your study.

Of note, as mentioned in our paper, we were able to confirm a lower prevalence of these symptoms than stated in other studies. ${ }^{3-9}$ This is in line with previous findings from Nielsen et al. ${ }^{2}$ indicating that the MDI is a more conservative tool and which may support the idea that the MDI should be evaluated as a screening tool for depressive disorders in SSc.

Received: July 11, 2020 Accepted: July 11, 2020 Published online: August 18, 2020

Correspondence: Elise Siegert, MD. Department of Rheumatology and Clinical Immunology, Charité-Universitatsmedizin Berlin, 10117 Berlin, Germany. Tel: 004930450613263 e-mail: elise.siegert@charite.de

\section{Citation:}

March C, Huscher D, Preis E, Makowka A, Hoeppner J, Buttgereit F, et al. Reply: Response to Letter to the Editor: Prevalence of Depressive Symptoms in Patients With Systemic Sclerosis. Arch Rheumatol 2020;35(3):460-461. 


\section{Declaration of conflicting interests}

The authors declared no conflicts of interest with respect to the authorship and/or publication of this article.

\section{Funding}

The authors received no financial support for the research and/or authorship of this article.

\section{REFERENCES}

1. March C, Huscher D, Preis E, Makowka A, Hoeppner $J$, Buttgereit F, et al. Prevalence, Risk Factors and Assessment of Depressive Symptoms in Patients With Systemic Sclerosis. Arch Rheumatol 2019;34:253-61.

2. Nielsen MG, Ørnbøl E, Bech P, Vestergaard M, Christensen KS. The criterion validity of the webbased Major Depression Inventory when used on clinical suspicion of depression in primary care. Clin Epidemiol 2017;9:355-65.

3. Roca RP, Wigley FM, White B. Depressive symptoms associated with scleroderma. Arthritis Rheum 1996;39:1035-40.
4. Thombs BD, Hudson M, Taillefer SS, Baron M. Prevalence and clinical correlates of symptoms of depression in patients with systemic sclerosis. Arthritis Rheum 2008;59:504-9.

5. Benrud-Larson LM, Haythornthwaite JA, Heinberg LJ, Boling C, Reed J, White B, et al. The impact of pain and symptoms of depression in scleroderma. Pain 2002;95:267-75.

6. Beretta L, Astori S, Ferrario E, Caronni M, Raimondi M, Scorza R. Determinants of depression in 111 Italian patients with systemic sclerosis. Reumatismo 2006;58:219-25.

7. Legendre $\mathrm{C}$, Allanore $\mathrm{Y}$, Ferrand I, Kahan A. Evaluation of depression and anxiety in patients with systemic sclerosis. Joint Bone Spine 2005;72:408-11.

8. Nietert PJ, Mitchell HC, Bolster MB, Curran MY, Tilley BC, Silver RM. Correlates of depression, including overall and gastrointestinal functional status, among patients with systemic sclerosis. J Rheumatol 2005;32:51-7.

9. Richards HL, Herrick AL, Griffin K, Gwilliam PD, Loukes J, Fortune DG. Systemic sclerosis: patients' perceptions of their condition. Arthritis Rheum 2003;49:689-96. 